\title{
argumentation
}

\section{Jon Roffe}

University of New South Wales, Australia

\begin{abstract}
In his review of my recent book, Abstract Market Theory, Johnson mistakes my investigation into the conditions and limits of probabilistic reasoning as a rejection of its sense and utility. The same misunderstanding also appears in a review by Munger published recently. In both cases this leads to a skewed and reductive understanding of my reconception of the relationship between price and value. In this response, I present an outline of the philosophical goals of Abstract Market Theory. My intent is not just to show that these reviews are incorrect in their presentation of my argument, but to also indicate why a philosophical perspective remains indispensable for our understanding of the market.
\end{abstract}

\section{Keywords}

Abstract market theory, possibility, philosophy, transcendental illusion

\section{Introduction}

The theory of probabilities is at bottom only common sense reduced to calculus.

(Laplace, 1902: 196)

For the possible is only the real with the addition of an act of mind which throws its image back into the past, once it has been enacted. But that is what our intellectual habits prevent us from seeing.

(Bergson, 2002: 229)

In this issue, Finance and Society has published a long review by Timothy Johnson that engages with an important, even decisive, new theoretical topos that is forming around the

\section{Corresponding author:}

Jon Roffe, Department of Philosophy, School of the Humanities and Languages, University of New South Wales, NSW 2010, Australia. Email: j.roffe@unsw.edu.au 
problematic of the market and at the intersection between philosophy and financial economics. Johnson's review, though it certainly moves the debate forward in a number of respects, is unfortunately undergirded by a series of misunderstandings that obscure much of what is at interest here.

Elie Ayache, the author of The Medium of Contingency (2016) and one of the books that Johnson engages with, has responded at length in this issue to the confusions that Johnson's presentation of the mathematics of probability seems to engage in, along with the lack of attention paid to both the actual practice of trading and the work of quants. I leave it to the reader to consult his important reframing of the questions at issue here. For my part, I will restrict myself to the claims Johnson makes about my book Abstract Market Theory (Roffe, 2016), and in particular the philosophical dimensions of this debate.

This is, unfortunately, a difficult endeavour, principally because the philosophical dimensions of the project of what l've called an abstract market theory are obscured by the approach that Johnson adopts. This is not to say that he is unaware of this dimension. Indeed, he acknowledges "there might be substantial links between the philosophy of Badiou, and presumably Deleuze and Meillassoux, and finance that are worth exploring" (Johnson, 2016) and makes reference himself to a number of other philosophers, including Hegel.

Unlike Johnson's discussion, Michael Munger's (2016) review of Abstract Market Theory in the Notre Dame Philosophical Review demonstrates no interest at all in or engagement with the philosophical dimension of the book - which is to say, the book itself. This, in addition to its extremely cavalier relationship to the book's contents, makes it a particularly shocking example of a poorly commissioned and curated review. I am more grateful as a result that Finance and Society is willing to publish a considered reply to Johnson's review, sufficiently confident in the quality of their commissioned reviews and the value of robust academic debate. If Munger's review is worth considering in this context, it is only because it advances however crudely - its case on the basis of the same three errors that Johnson also makes. Both reviewers misread the book by overlooking and displacing its specifically philosophical character. Consequently, both reviews misrepresent what the book actually argues, above all with respect to the status of probability and probabilistic models. I will begin by considering the explicit claims they make about Abstract Market Theory.

\section{Returning to the text}

Johnson and Munger's reviews of my book dwell on a very limited part of its argumentation. Johnson's remarks only address the first two chapters in any detail. Munger's review, on the other hand, appears to only consider three pages of the book. What this means is that most of the course of my argument, and the many intermediary conclusions that it includes, are completely ignored. There are many examples, but let me just select a single one as exemplary. Here is Johnson (2016, citing Roffe, 2015: 4):

In his introduction, Roffe states:

the argument advanced here involves (1) developing a concept of price, (2) developing a concept of the market, and making clear the nature of the market-price relationship, and (3) with these concepts in hand, situating in precise terms the regime of the social in relation to that of the market

and Roffe proceeds by first discussing probability before moving onto prices. The consequence of this is that we have no clear articulation of what is meant by 'the market' until we are presented by Fama's definition in relation to the Efficient Markets [sic] Hypothesis. 
The elision of the difference between 'the market' and 'markets' here is symptomatic, and not only insofar as it skips over two of the most important problems at stake: is there a single market to which markets plural are related? And if so, what is this relationship? But take note of the claim that no definition of 'the market' is provided in the first 123 pages of my book. Leaving aside the implication that I endorse Fama's position - a position I unambiguously reject (Roffe, 2015: 122-4) - what do we find if we glance through these pages? Statements like the following:

The market is the unconscious of our contemporary situation. (Roffe, 2015: 50)

The market is a form of integral co-presence [...] there is no 'absolute elsewhere' in the market, and every price is therefore implicated in every other. (83)

The market is the social surface. (106)

I do not claim, of course, that such propositions about the nature of the market - of which these are only a limited selection - will be meaningful in isolation. In fact, they constitute composite definitions of the market, and, indeed, the entire first part of book, entitled 'The Being of the Market', addresses exactly this question. But they already provoke us to ask how we ought to interpret this claim of Johnson's, other than to conclude that he has simply not read the book.

Johnson also raises the issue of the interpretation of texts. He writes of my book that:

[w]hile the argument is well presented it conveys the impression that it is principally a work of hermeneutics ... which does not actually get to grips with the actual phenomenon of 'the market'. (Johnson, 2016)

The construction of a philosophy of the market cannot, in my view, draw exclusively from literature in finance, which is why so many other resources are bought to bear: for instance, Hilbert, Quine, Foucault, Freud, Bergson, Lacan, Ruyer, Nietzsche, Mauss, Bataille, Leibniz, and Clastres, not to mention Ayache, Deleuze and Meillassoux. And of course, to the extent that I wished to lay out the process of conceptual construction and demonstrate the heritage of the components I was putting into play, there is also a great deal of effort to provide clear summaries of these components.

The real problem here is in this invocation of the actual phenomenon of the market. I detect in it a familiar act of disciplinary boundary drawing that contradicts the gesture of Johnson's title ('The necessity of multi-disciplinary scholarship for finance'). Johnson is implying, it seems to me, that if the only resources that are relevant for thinking the market have already been provided by financial theory, why do we need other disciplinary contributions? More to the point, when just such resources are provided, why is it that the clear and detailed presentation of what they provide is so easily dismissed as 'hermeneutics'?

Incidentally, this point also seems to contradict the more general claim that Johnson makes of my book, namely that it has a very slight relationship to other theoretical works. He claims, for instance, that "the basis of his [my] understanding of markets comes from a few principal sources: Ayache, Taleb, Fama and Graeber" (Johnson, 2016). It is true that Ayache's work is decisive for the account provided in Abstract Market Theory, and I remain convinced that it has made the essential set of opening moves that any philosophy of the market will have to follow. The other three figures, though, are very marginal to the argument indeed, each of them being considered in brief and straightforwardly critical fashion. 
The most pronounced version of this line of attack comes in Johnson's (2016) conclusion, where we read:

The really disappointing consequence of the limited scholarship that both Ayache and Roffe rely on is that there might be substantial links between the philosopy of Badiou, and presumably Deleuze and Meillassoux, and finance that are worth exploring. ${ }^{1}$

This claim is quite stunning. For in fact the entire book, with the exception of the second chapter on the price/value distinction, pursues exactly this line of investigation. Indeed, it advances a theory of the market thoroughly Deleuzean in character, backed up with chapters of detailed conceptual analysis. This involves, of course, a lot of textual work - 'hermeneutics' - but the point is throughout to deploy Deleuze, Meillassoux, Ruyer, and others in order to create a concept of the market. Now, whether or not Johnson agrees with the content of my argument, it is completely incorrect to say that I do not make the attempt to bring finance and philosophy into contact.

In sum, Johnson accuses Abstract Market Theory of failing to engage with the full range of relevant scholarly work, and for being too focused on textual exposition. He sees my book as being too narrow in its philosophical ambit, despite the evidence of the text itself. Like every square circle, the fashioning of this one is well outside of my abilities.

These kinds of misprisions are also repeated in Munger's text. To cite a single example:

A minor difficulty is that in several places, Roffe highlights 'bugs' that are in fact features. On page 11 he introduces us to the (correct) idea that price movements in 'thick' (that is, heavily traded) markets are stochastic. This notion recurs at several points, and I think that he intends this observation as a claim that markets, whatever they do measure, are not revealing information about 'value.' How could random movement have anything to do with value, which is solid and important and objective? (Munger, 2016)

I reject, first of all, this characterisation that I present any feature of the market as 'bugs'. The book is a work of construction, not critique, and indeed the very first page rules out such a moralistic approach. I simply aim to define the market. This passage also reveals that Munger did not grasp (or read) the definitions of value and price that open the second chapter, and which form the foundations of the argument of the book. Value, I argue, is not and could not be 'objective' - indeed, it is essentially social and qualitative in character. Correlatively, the discussion of the pricing process as stochastic is an entrée (it appears right at the start of the first chapter) to the more significant concept of contingency, which comes right after it.

In this same passage, Munger repeats Johnson's gesture of exclusion: 'we', i.e. those working in finance, understand the market, and if 'you', i.e. those who do not work in finance, question the terms with which we prosecute our analyses, then you clearly have nothing to contribute. Or, to use Johnson's (2016) kinder turn of phrase: “Technically I think Roffe's line is weak".

\section{The transcendental critique of possibility}

Unfortunately, the material which does sustain the attention of these two reviewers appears to have been subject to a serious misunderstanding. The major issue here, at the heart of Johnson's critique of both Ayache's book and my own - and also what I take to be the motivation for Munger's ill-informed review - is the status of probability and probabilistic modelling. 
Abstract Market Theory presents three philosophical arguments against the orthodox conception of pricing, all of which turn around the category of the possible. Ayache and I both make reference to the first two, even though it is from different angles and for slightly different reasons. This is to say that we share these arguments, rather than my work being founded on Ayache's reading of them, as Johnson suggests. There are even significant differences and disagreements in our two ways of advancing them, but this is not the place to dwell on them here - I invite the reader to consider the texts themselves.

The first argument - I will only briefly note them here - is derived from the work of Quentin Meillassoux, and his small classic of recent philosophy, After Finitude (2008). Meillassoux's book presents a novel and forceful argument asserting the absolute primacy of contingency - the world could change at any moment for no reason whatsoever. Now, the contingency in question is identical to neither stochastic randomness, nor to either risk or Knight's well-known category of uncertainty that Munger claims I both ignore and unwittingly presuppose. ${ }^{2}$ At issue is not knowledge of the real but the real itself; we are dealing with an "absolute ontological truth" (Meillassoux 2008: 71). If contingency is radical in this way, then the category of the possible cannot have any purchase on reality as such.

The second argument is first advanced by Henri Bergson (2002) in a fantastic little essay 'The Possible and the Real'. Bergson argues that the very category of the possible is logically and temporally inconsistent. In a sense, this is the main critical point on which the argument of Abstract Market Theory rests. The category of the possible presupposes, he says, that "the possibility of things precedes their existence. They would thus be capable of representation beforehand; they could be thought of before being realised" (Bergson, 2002: 228). But note the ontological presupposition that this involves - that the possible has a being prior to the real that it may become. What kind of being could the possible possess, could possible states of the world possess? But the real problem lies elsewhere, namely in the fact that the possible worlds which must precede their realisation nevertheless resemble the world that has not yet arrived. What explains this resemblance that, despite being to some degree uncertain (probable and not necessary), characterises possible images of the world?

Bergson's conclusion is that the possible cannot come before the real, and that the images of what this present moment 'could have been' are created in the present and retrojected by, he says, "an act of mind" (Bersgon, 2002: 229). It is not possible that the pair of dice I am about to throw will come down on two sixes, or on any other outcome. As Bergson put it, any predicted outcome "will have been possible" (Bergson, 2002: 229), and here the future anterior marks the retrojection characteristic of all probabilistic thinking.

The third argument, one that Ayache himself does not deploy in any detail, is based on the analysis of temporality that Deleuze (1995: 85-91) advances in Difference and Repetition. In essence, it contends that Meillassoux's conclusion about contingency overlooks the role played by time, ${ }^{3}$ and that the irreducibility of temporality is the true ground of contingency. Time guarantees contingency - the future is nothing other than the empty form of time itself, the inflexible necessity of a 'next'.

It should be clear, then, that when I assert that "Probability and its root possibility are incoherent concepts that rely on incompatible logical and temporal predispositions" (Roffe, 2016: 150), this is not "based on Ayache's arguments" (Johnson, 2016), but on these critiques of the concept of possibility at the level of its philosophical presuppositions.

Now, crucially, none of these arguments lead me to conclude that probabilistic claims are completely unfounded, useless or deceptive, in total or to any given degree (a position advanced by Taleb and endorsed by Munger). What they do provide us with is a way of correctly seeing what, and under what conditions, probabilistic reasoning can legitimately 
contribute to knowledge. What they all assert is that probabilistic reasoning has conditions that contradict our common understanding of what it can tell us. So my interest in the first chapter of Abstract Market Theory is not to say that all use of modelling is deluded or wrong, but that all use of probabilistic modelling involves us in unavoidable misunderstandings about reality. The two quotes that form my epigraph here make precisely the same point from the perspective of mathematics and philosophy, respectively: common sense is an unavoidable framework through which we encounter and organise the world. But this neither means that we must do away with its stabilising function (which cannot be done), nor that we should simply conclude that common sense actually tells us about the nature of reality.

Since Kant, these kinds of presuppositions, which are covered over in the very course of human experience, have borne the name 'transcendental illusions'. Mere misunderstandings, deception and even cognitive bias to a certain degree can be exposed and done away with, but transcendental illusions are built into the structure of human experience and knowledge. The genuine question, in light of the serious flaws in the concept of possibility, is what grounds and limits its deployment in the search for knowledge of any kind. This is a philosophical question, not one susceptible to empirical investigation because such investigations presuppose what is in question. In Ayache's (2010: 28) fine formulation, this is the question that would characterise any "transcendental philosophy of the Black Swan" - what are the conditions for conceiving of events, themselves radically contingent, in terms of relative likelihood?

So we can see, finally, that Johnson's (2016) assertion - "Without commenting on the strengths of Roffe's analysis, its weakness rests on an over-reliance of Ayache's understanding of probability theory" - does not come to grips with the arguments in Abstract Market Theory about the nature of possibility and probability.

Worse though is Munger's perplexing conclusion that my entire analysis confuses model and reality.

Roffe's analysis rests on a plainly false basic premise. 'Definition 1' asserts that 'The orthodox conception of the market is organized around the probabilistic modeling of the market'. But this confuses the workings of the market as an objective process playing out empirically, in the world, with the abstract models that human modelers, in this case economists, use to understand and predict the market. (Munger, 2016, citing Roffe 2016: 150)

I entirely fail to see how the assertion that "The orthodox conception of the market is organised around the probabilistic modelling of the market" confuses model and reality. Fortunately, Munger himself provides us with a very clear example of this kind of confusion when he answers his own rhetorical question - "How could random movement have anything to do with value, which is solid and important and objective?" - by writing that "The problem is that the so-called 'efficient markets hypothesis' is operating in the background" (Munger, 2016). My claim that mainstream economics conceives of markets in probabilistic terms is a non-contradictory and prima facie uncontroversial empirical claim. Munger's claim that a hypothesis is really and materially operating in the background of the pricing process is to conflate the order of real economic process with that of theoretical speculation, to confuse model and reality.

\section{Philosophy's place}

I would like to conclude this brief response by considering again the most general criticism that both Johnson and Munger level at Abstract Market Theory - that it is theoretically under- 
resourced and expresses a view of the market that could do from a large dose of research in economics and the social sciences. Munger criticises me for not having paid attention to Knight and Hayek; Johnson for not having read enough probability theory, and for having consequently sequestered myself away from the resources in philosophy that may have been of the most use.

This claim is motivated by a certain vision of philosophy that I do not share. The goal of philosophy is not to confirm empirical description but to grasp the formal grounds for empirical reality and its description. Consequently, to treat philosophy as if it must obey the rules of empirical disciplines like history, sociology or economics appears to me to miss the point.

From its first pages to its last, Abstract Market Theory dwells on the necessity of distinguishing philosophy from the social sciences - including history, which I certainly did not "ignore" (Johnson, 2016). Indeed, the opening pages of the final chapter of the book, 'Temporality', address exactly why the social sciences are necessary, as well as why their contribution is necessarily limited (Roffe, 2016: 134-8). In short, the social sciences and philosophy have different objects. The former addresses social organisation in its concrete diversity and the tendencies that this diversity manifests. The latter addresses formal questions and transcendental presuppositions. Or, as I put it in Abstract Market Theory, "philosophy is the life of form in thought" (Roffe, 2016: 148).

That "price is anterior to probability" (Johnson, 2016) in historical terms is not what is essential from the philosophical perspective, which aims instead to grasp the logical, formal or transcendental presuppositions of social organisation in its history. With respect to the main theme of this response, at issue are the relations of presupposition that hold between price (and its place, the market) and the probabilistic reasoning that can only flourish by mistaking price as value.

Now, it may be, as both Johnson and Munger assert, that such claims are hardly novel. But if this is so, it would be difficult indeed to understand why two scholars so familiar with this field of enquiry had such trouble recognising them.

\section{Notes}

1. I leave aside here any critical detail concerning Johnson's (2016) outline of Badiou's philosophy, which is remarkable for presenting the beginnings of a good summary of the latter's system in Being and Event before demonstrating, with his invocation the market process and traders' disagreements, a superficial grasp indeed on the distinction between knowledge and truth that is so important to Badiou.

2. In light of his invocation of Knight, it was amusing to read Munger's (2016) claim that "Roffe's critique of models, then, simply restates the nearly hundred year old (and widely recognized) critique made by Knight. In this, Roffe is correct, but unoriginal" - amusing because I immediately recalled the well-known opening of Knight's 'Author's Preface' in Risk, Uncertainty and Profit: "There is little that is fundamentally new in this book" (Knight, 2014: vii).

3. For a longer and more detailed presentation of this argument see Roffe (2012).

\section{References}

Ayache, E. (2010) The Blank Swan: The End of Probability. Chichester: Wiley \& Sons. Ayache, E. (2015) The Medium of Contingency: An Inverse View of the Market. New York, NY:

Palgrave Macmillan. 
Bergson, H. (2002) The possible and the real. In Ansell-Pearson, K. and J. Mullarkey (eds.) Bergson: Key Writings. London: Continuum, 223-232.

Johnson, T. (2016) The necessity of multi-disciplinary scholarship for finance: On Ayache and Roffe. Finance and Society, 2(2): 189-204.

Knight, F. (2014). Risk, Uncertainty, and Profit. Eastford, CT: Martino Fine Books.

Laplace, P-S. (1902) A Philosophical Essay on Probabilities, trans. F. Truscott and F. Emory. London: John Wiley and Sons.

Meillassoux, Q. (2008) After Finitude: An Essay on the Necessity of Contingency, trans. R. Brassier. London: Continuum.

Munger, M. (2016) Review of Abstract Market Theory. Notre Dame Philosophical Review. Available at: <https://ndpr.nd.edu/news/68800-abstract-market-theory/>. Accessed 14 October 2016.

Roffe, J. (2012) Time and ground: A critique of Meillassoux's speculative realism. Angelaki, 17(1): 5767.

Roffe, J. (2015) Abstract Market Theory. Basingstoke: Palgrave. 